\title{
Prospective of Medical Cost for Renal Failure for Sex and Age Group in Range 2012-2050: Case of Mexico
}

\author{
Dora E. Ledesma-Carrión ${ }^{1}$, Lidia Hernández-Hernández ${ }^{1}$ and María Teresa Leonor Muciño-Porras ${ }^{2}$ \\ 1. Dirección General Adjunta de Investigación de la Dirección General de Integración, Análisis e Investigación, Instituto Nacional \\ de Estadística y Geografía, Av. Patriotismo 711 Torre A Piso 4 Col. San Juan Mixcoac, México D. F. 03730 México \\ 2. Subdirección de Capacitación de la Dirección General de Administración, Instituto Nacional de Estadística y Geografía, Av. \\ Patriotismo 711 Torre A Piso 2 Col. San Juan Mixcoac, México D. F. 03730 México
}

\begin{abstract}
Medical costs are calculated for renal failure for all age groups of Mexican people and sex in range of 2012-2050. Probabilities of entrance or disease detection, permanence or in treatment and departure or death are calculated for each age group and sex. The maximum probabilities for each case are 5.36\% (60-64), 6.25\% (0-4) and $0.48 \%$ (85+) for male. Analogously, for female are $5.56 \%(60-64), 5.24 \%(0-4)$ and $0.32 \%(85+)$, respectively. The treatment medical costs are not similarly between men and women. The maximum number of people in treatment is between (0-4) and (20-24, male. 25-29, female) years old. The number of patients varies between 5 and 19 years of age, from 30 years of age decreases the number of patients up to age 69 years. After that it increase again.
\end{abstract}

Key words: Medical costs, prospective, aging, health, renal failure.

\section{Introduction}

Mexican food is varied but rich in carbohydrates and fats, recent advances in medicine have shown that the change of cane sugar by fructose as a sweetener in the Mexican diet is largely responsible along with hereditary factors of physical deterioration of the Mexican population: obesity, diabetes mellitus, hypertensive diseases, renal failure (RF) and chronic-disease degenerative [1,2].

This work shows the economic impact over a horizon of 2012-2050 of RF in terms of percentages of GDP (gross domestic product), for the three scenarios: base, optimal and worse. The base scenario is calculated by adjusting a model AR (2) MA (2) [3] with weighting, the other two are given by experts and both depend on the effect of energy and labor reforms.

Population projections by CONAPO whose methodology appears on the official website [4] and

Corresponding author: Dora Elena Ledesma-Carrión, Ph.D., research fields: mathematical models, operations research and material science. decadal cohort of number of patients and unit costs for some diseases IMSS beneficiaries were used $[5,6]$. IMSS information is not showed by age group neither sex (patients in treatment). New cases information appears since 1980 up to 1990 by big age group and sex and 1991-2011 by age group. Deceased people by RF are presented by age and sex.

The available information is from public institutions: Ministry of Health (Secretaria de Salud, SS [7-10]), National Population Council (Consejo Nacional de Poblacion, CONAPO [4]), Mexican Institute of Social Security (Instituto Mexicano del Seguro Social, IMSS $[5,6,11])$, National Institute of Statistics and Geography (Instituto Nacional de Estadistica y Geografia, INEGI [12]) and private: Mexican Association of Insurance Institutions (AMIS (Asociacion Mexicana de Instituciones de Seguros)) and hospitals.

The cost of this disease is high for its treatment and its duration. As insured persons by IMSS represent $40 \%$ of the population, IMSS data are taken as 
sampling. The Mexican health system (SS) covers the following institutions: IMSS, Institute for Social Security and Services for State Workers (Instituto Mexicano de Seguridad Social y Servicios para los Trabajadores del Estado, ISSSTE), Popular Insurance (Seguro Popular, SP-IMSS), Oil Company (Petroleos Mexicanos, PEMEX), Ministry of Defense (Secretaria de la Defensa Nacional, SEDENA), Ministry of Navy (Secretaria de Marina, SEMAR), private institutions and other public institutions, so the numbers of deaths and new cases are representative of the population.

The paper is organized as follows: Section 2 explains the methodology used to solve the problem of calculating medical costs for this disease; Section 3 presents results and Section 4 expresses the conclusions.

\section{Methodology}

The proposed model is stochastic [13] with entrance, in treatment and death probabilities by RF, population, number of patients and unitary cost at time $t$ by age group and sex (stock).

The probabilities are calculated for each year, $t$, as

$$
\frac{\operatorname{Pr}(\text { death, age, sex; } ;)=}{\text { \# death by the disease }(a g e, \operatorname{sex} ; t)}
$$

$\operatorname{Pr}($ new cases, age, sex; $t)=$ \# new cases or \#detected disease (age, sex; $t$ ) population (age, sex; $t)$

$\operatorname{Pr}(+1$, age, sex; $t)=$ \#people who have survived the disease one more year (age, sex; $t$ ) population (age, sex; $t)$

The model diagram is showed in Fig. 1. Several considerations must be taken by each patient's condition.

Deaths. It works with the records of the SS with respect to age, sex and cause key, excluding unspecified. It has the historical 1990 to 2011. Curve fitting are applied to these data by OLS (ordinary least-squares) after the made the transformation of Eq. (4). In most cases it is the exponential. The growth rates are denoted as $\lambda$. Prospective is constructed following behavior given these rates, for 2012-2050 taken as input data 2011. The correlation coefficients of curve fitting are showed in Table 1.

$$
\begin{gathered}
\operatorname{death}_{t}=\text { death }_{0} e^{\lambda t} \Rightarrow \\
\operatorname{Ln}\left(\text { death }_{t}\right)=\operatorname{Ln}\left(\text { death }_{0} e^{\lambda t}\right)=\operatorname{Ln}\left(\text { death }_{0}\right)+\lambda t
\end{gathered}
$$

The Eq. (1) is calculated using both prospective, the population and the exponential behavior of deaths by RF. This latter based on the high correlation coefficients by age group and sex shown in Table 1 .

Behavior of deaths was analyzed. The age groups 5-9 and 15+ showed an exceptional exponential behavior with correlation coefficients greater than $96 \%$ for female and $98 \%$ for male.

New cases. From the database of the SS tables of major diseases are obtained by age group $(<1,1-4,5-9$, $10-14,15-19,20-24,25-44,45-49,50-59,60-65 \&$ $65+)$. Information was obtained from 1990-2011 data which its trend behavior and basic statistics (mean and standard deviation) were analyzed. In case non-trend was chosen to simulate an exponential growth between the extreme values for the entire period. As a base scenario was chosen the trend values as first option and minimum among all the options as second choice.

Eq. (2) is calculated using both prospective, the population and the exponential behavior of new cases by RF.

For new cases exhibit this behavior with correlations of $56 \%$ for women and $86.05 \%$ for men in general. The probabilities of entrance, in treatment

Table 1 Correlation coefficients for exponential behavior (death).

\begin{tabular}{llllll}
\hline Age groups & Male & Female & Age groups & Male & Female \\
\hline $0-4$ & & & $45-49$ & 0.89 & 0.80 \\
$5-9$ & 0.85 & 0.81 & $50-54$ & 0.91 & 0.85 \\
$10-14$ & & & $55-59$ & 0.95 & 0.87 \\
$15-19$ & 0.92 & 0.94 & $60-64$ & 0.95 & 0.81 \\
$20-24$ & 0.97 & 0.78 & $65-69$ & 0.95 & 0.75 \\
$25-29$ & 0.93 & & $70-74$ & 0.97 & 0.91 \\
$30-34$ & 0.88 & & $75-79$ & 0.95 & 0.94 \\
$35-39$ & 0.93 & 0.78 & $80-84$ & 0.97 & 0.96 \\
$40-44$ & 0.95 & 0.80 & $85+$ & 0.98 & 0.92 \\
\hline
\end{tabular}


and death to RF are dynamics and they are different in each stage. Their dynamic changes are gotten by LSO. Tables of these dynamic changes by age group are shown in the appendix.

In treatment. IMSS data were used to rebuild the intermediate years. The method Runge-Kutta was applied to the exponential growth rates per period. Then data were redistributed according to death rates of SS for age groups. Subsequently normalized with respect to the prospective of the IMSS. The initial value is the amount of the average proportion of deaths ${ }^{1}$ by age group by sex (2003-2011) multiplied by the number of patients treated according to IMSS prospective.

Data from 2011 patients in treatment are obtained by extrapolating the values of 2012 compared to exponential growth rates (2012-2020) of its prospective. The cases of initial values are the maximum, minimum and average in the period. After these are distributed by age and sex as mentioned in the previous paragraph.

Eq. (3) is calculated using both prospective, the population and the exponential behavior of in treatment patients by RF. As the number of in treatment patients are IMSS data (sample), these were analyzed and calculated their behavior and prospective of both beneficiaries of the IMSS and beneficiaries who have survived the disease one more year. Latter, the probabilities by age group by sex by each year were gotten applying Eq. (3). After, these probabilities were input to make inference to population.

The AMIS published in 2011 the morbidity rate of RF for each 10,000 (Table 2).
Redistribution by age group (2012-2050) can be calculated using standard growth rates (about the death) following the general prospective IMSS or initial values using any of the three values obtained from the ratios of deaths by group age by sex by disease (1990-2012): average, maximum or minimum, and from the initial value to apply the before mentioned growth rates. The scenarios I, II and III use the average, maximum and minimal values as initial value (2011), respectively.

\subsection{Gross Domestic Product Scenarios: Basis, Optimal and Worse}

Base Scenario. Quarterly GDP (gross domestic product) data since 1996-I up to 2012-IV current prices are applied to AR (2) MA (2) model (Eq. (5)). Adjusted data are deflated to base year 2012. In an ideal situation, the sequence diagram should capture the requirements in the forms of good scenarios. Bad scenarios need to be detected automatically. Users tend to over complicate the sequence diagrams. Unfortunately, there is little or no indication of what constitutes a good sequence diagram. Ideally, it should be possible to lift off an executable specification for checking the validity of the diagram.

$$
\begin{gathered}
P I B_{t}=1.037568 P I B_{t-2}+ \\
+[A R(2)=0.730942, M A(2)=-0.937709] \\
1996 \leq t \leq 2012
\end{gathered}
$$

From Table 3, AR process is stationary and ARMA model is invertible. The model presents positive serial correlation because of Durbin-Watson statistical is between 1 and 2. Covariance matrix values appear in Table 4.

Table 2 Morbidity rate of renal failure for each 10,000 (2011).

\begin{tabular}{llllll}
\hline Age group & Distribution of insured male & RF (N10-N19) & Age group & Distribution of insured female & RF (N10- N19) \\
\hline $0-20$ & $29 \%$ & 63 & $0-20$ & $26 \%$ & 78 \\
$21-35$ & $30 \%$ & 92 & $21-35$ & $33 \%$ & 119 \\
$36-50$ & $29 \%$ & 112 & $36-50$ & $29 \%$ & 125 \\
$51-65$ & $10 \%$ & 279 & $51-65$ & $10 \%$ & 172 \\
+65 & $2 \%$ & 3,846 & +65 & $1 \%$ & 4,109 \\
TOTAL & $100 \%$ & 4,391 & TOTAL & $100 \%$ & 4,603 \\
\hline
\end{tabular}




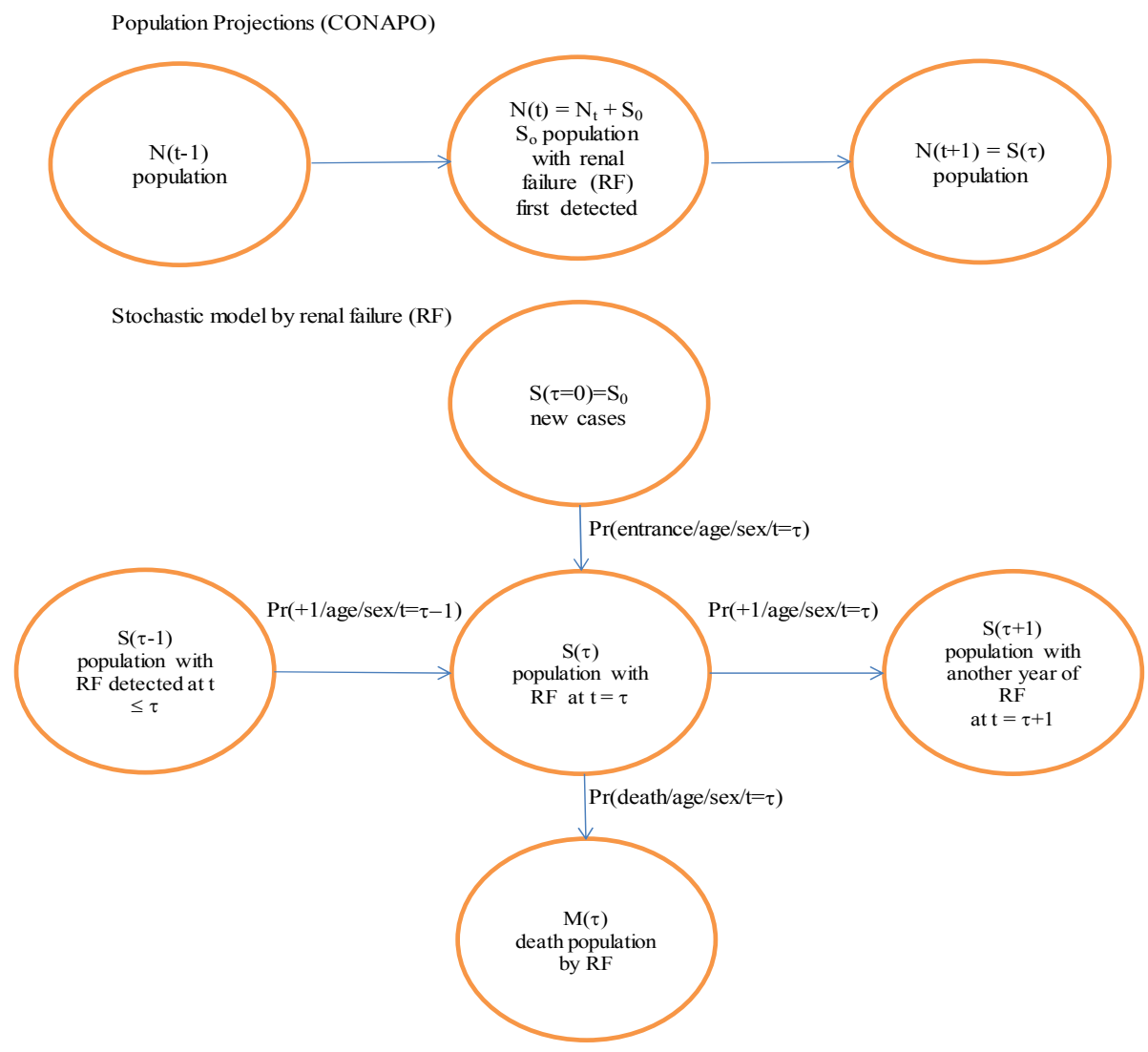

$\operatorname{Pr}($ entrance/age/sex/t): Entrance or detected disease probability for age for sex at time $\mathrm{t}$

$\operatorname{Pr}(+1 /$ age/sex/t): Suffering a year over the disease probability by age by sex at time $t$

$\operatorname{Pr}($ death/age/sex/t): Death probability by RF by age by sex at time $t$.

Fig. 1 Schematic model. Started CONAPO population projections estimated population with hypertensive diseases, new cases and dying from renal failure from 2012 to 2050.

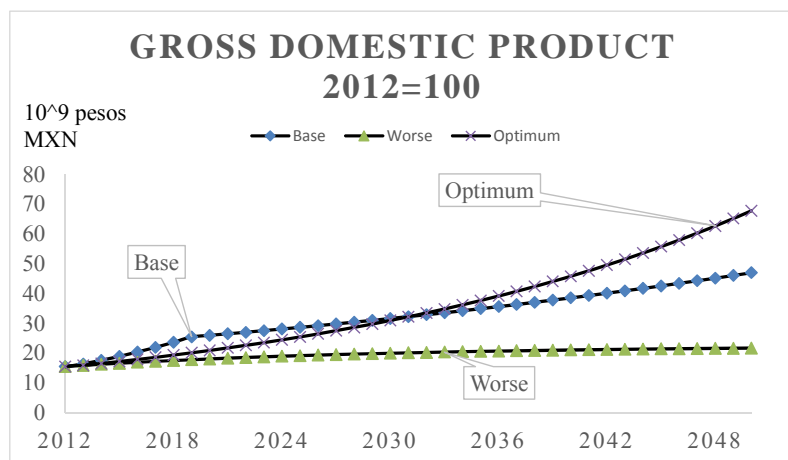

Fig. 2 Curves fitted for each scenarios of gross domestic product are showed.

Table 3 Statistical parameter of model AR (2) MA (2).

\begin{tabular}{ll}
\hline Parameters & \\
\hline $\mathrm{R}^{\wedge} 2=98.99 \%$ & Inv. AR Root $(0.85,-0.85)$ \\
& Inv. MA Root $(0.97,-0.97)$ \\
$\mathrm{S}_{\varepsilon}=3.66 \times 108$ & $\mathrm{t}-$ Student $(433.15,8.79,-23.86)$ \\
$\mathrm{n}=64$ & $\mathrm{D}-\mathrm{W}=1.160196$ \\
\hline
\end{tabular}

Table 4 Covariance matrix of model AR (2) MA (2).

\begin{tabular}{llll}
\hline coefficients & \multicolumn{3}{l}{} \\
\cline { 2 - 4 } & GDP(-2) & AR (2) & MA (2) \\
\hline GDP(-2) & $5.74 \mathrm{E}-06$ & $-7.41 \mathrm{E}-05$ & $-2.26 \mathrm{E}-05$ \\
AR (2) & $-7.41 \mathrm{E}-05$ & 0.006918 & -0.000999 \\
MA (2) & $-2.26 \mathrm{E}-05$ & -0.000999 & 0.001545 \\
\hline
\end{tabular}

The increasing GDP was 2.5\% (January 2013) fall dawn 1.7\% (December 2013). Average rate in June 2014 was $3.1 \%$ (fall dawn up to $2.5 \%$ ) and last semester is expected $1.7 \%$. The government expects increasing rates during 2015 between $2.5 \%$-3.5\%. In 2016 , rates could be of $3.0 \%-3.1 \%$ and in $2017-2050$ of $3 \%$. If energy and labor reforms are successful, the GDP growth rates could be of up to $7 \%$ from 2020 .

Optimum scenario. Upper limits of the ranges of the above paragraph. 
Worse scenario. Lower limits of the ranges of the above paragraph.

\subsection{Probabilities of Entrance, in Treatment and Death for Renal Failure.}

Dynamics probabilities prospective by patient condition by age group by sex by year are gotten from IMSS prospective for in treatment patients (Table 5) and applied to Runge-Kutta approximation to reconstruction year by year. Late, death data historic distribution by age groups and its prospective was applied to Table 6 data. Maximal rate for male is $0.47 \%$ and $0.54 \%$ for female at 2012 . These rates are larger for women as men throughout the period. NOTE: In the IMSS prospective of in treatment patients, their rates are decreasing from 2021 to differences obtained from the analysis of historical data from 1990 to 2011 .

In the cases of death and new cases condition, dynamics probabilities prospective are fitted by LSO. SS data are age groups.

\section{Results}

From Figs. 3 and 4, comparing two arbitrary years,
2019 and 2040, RF medical costs are higher for women than men about $0.053 \%$ and $0.088 \%$ of GDP, respectively, for base scenario. To worse scenario the differences are $0.076 \%$ and $0.161 \%$ for each reference year. To optimum scenario are $0.067 \%$ and $0.074 \%$. All are in absolute terms.

If the initial value of patients in 2011 is the historical minimum, the differences in medical costs versus maximum are 0.093\% (2019) and 0.0975\% (2040) for male. For female, the costs differences are $0.128 \%$ and $0.134 \%$, respectively.

For historical minimum initial value versus average initial value, the differences in medical costs for male are $0.0398 \%$ (2019) and 0.0415\% (2040) and for female are $0.0544 \%$ and $0.0568 \%$, respectively.

From Figs. 5, 6 and 7, the medical costs represent $5.97 \%$ (2019) and 9.35\% (2040) for 50 and more years old male respect all disease population. For female, the costs are $8.31 \%$ and $13.97 \%$, respectively.

The maximum number of people in treatment is between 0-4 and (20-24 (male), 25-29 (female) years old. The sick RF cases are going to shoot up after $70+$ years old for male and $80+$ for female.

Table 5 IMSS prospective for in treatment patients of renal failure.

\begin{tabular}{ll}
\hline Parameters Increasing range $[9,10]:$ & Rates of in treatment patients for \\
\hline$\lambda 12012-2020$ & $9.7 \%$ \\
$\lambda 22021-2030$ & $4.2 \%$ \\
$\lambda 32031-2040$ & $2.3 \%$ \\
$\lambda 42041-2050$ & $1.0 \%$ \\
$\lambda 2012-2050$ & $4.0 \%$ \\
\hline
\end{tabular}

Table 6 Probabilities by patient condition by sex by year (2012-2050).

\begin{tabular}{|c|c|c|c|c|c|c|}
\hline \multirow[b]{2}{*}{ year } & \multicolumn{2}{|c|}{ Enter } & \multicolumn{2}{|c|}{ Treatment } & \multicolumn{2}{|c|}{ Death } \\
\hline & male & female & male & female & male & female \\
\hline 2010 & $0.37 \%$ & $0.53 \%$ & $0.53 \%$ & $0.33 \%$ & $0.01 \%$ & $0.01 \%$ \\
\hline 2011 & $0.44 \%$ & $0.69 \%$ & $0.54 \%$ & $0.37 \%$ & $0.01 \%$ & $0.01 \%$ \\
\hline 2012 & $0.46 \%$ & $0.71 \%$ & $0.79 \%$ & $0.60 \%$ & $0.01 \%$ & $0.01 \%$ \\
\hline 2013 & $0.48 \%$ & $0.73 \%$ & $0.85 \%$ & $0.64 \%$ & $0.01 \%$ & $0.01 \%$ \\
\hline 2014 & $0.49 \%$ & $0.76 \%$ & $0.92 \%$ & $0.69 \%$ & $0.01 \%$ & $0.01 \%$ \\
\hline 2015 & $0.51 \%$ & $0.78 \%$ & $0.99 \%$ & $0.74 \%$ & $0.01 \%$ & $0.01 \%$ \\
\hline 2016 & $0.54 \%$ & $0.81 \%$ & $1.06 \%$ & $0.80 \%$ & $0.02 \%$ & $0.01 \%$ \\
\hline 2017 & $0.56 \%$ & $0.83 \%$ & $1.15 \%$ & $0.86 \%$ & $0.02 \%$ & $0.01 \%$ \\
\hline 2018 & $0.58 \%$ & $0.86 \%$ & $1.24 \%$ & $0.93 \%$ & $0.02 \%$ & $0.01 \%$ \\
\hline
\end{tabular}


(table 6 continued)

\begin{tabular}{|c|c|c|c|c|c|c|}
\hline \multirow[b]{2}{*}{ year } & \multicolumn{2}{|c|}{ Enter } & \multicolumn{2}{|c|}{ Treatment } & \multicolumn{2}{|c|}{ Death } \\
\hline & male & female & male & female & male & female \\
\hline 2019 & $0.60 \%$ & $0.89 \%$ & $1.33 \%$ & $1.00 \%$ & $0.02 \%$ & $0.01 \%$ \\
\hline 2020 & $0.63 \%$ & $0.92 \%$ & $1.43 \%$ & $1.07 \%$ & $0.02 \%$ & $0.01 \%$ \\
\hline 2021 & $0.65 \%$ & $0.95 \%$ & $1.46 \%$ & $1.09 \%$ & $0.02 \%$ & $0.01 \%$ \\
\hline 2022 & $0.68 \%$ & $0.98 \%$ & $1.49 \%$ & $1.11 \%$ & $0.02 \%$ & $0.01 \%$ \\
\hline 2023 & $0.71 \%$ & $1.01 \%$ & $1.52 \%$ & $1.13 \%$ & $0.02 \%$ & $0.02 \%$ \\
\hline 2024 & $0.74 \%$ & $1.04 \%$ & $1.54 \%$ & $1.15 \%$ & $0.02 \%$ & $0.02 \%$ \\
\hline 2025 & $0.77 \%$ & $1.08 \%$ & $1.57 \%$ & $1.17 \%$ & $0.02 \%$ & $0.02 \%$ \\
\hline 2026 & $0.80 \%$ & $1.11 \%$ & $1.60 \%$ & $1.19 \%$ & $0.02 \%$ & $0.02 \%$ \\
\hline 2027 & $0.83 \%$ & $1.15 \%$ & $1.63 \%$ & $1.21 \%$ & $0.02 \%$ & $0.02 \%$ \\
\hline 2028 & $0.86 \%$ & $1.18 \%$ & $1.66 \%$ & $1.24 \%$ & $0.02 \%$ & $0.02 \%$ \\
\hline 2029 & $0.90 \%$ & $1.22 \%$ & $1.69 \%$ & $1.26 \%$ & $0.02 \%$ & $0.02 \%$ \\
\hline 2030 & $0.93 \%$ & $1.26 \%$ & $1.72 \%$ & $1.28 \%$ & $0.02 \%$ & $0.02 \%$ \\
\hline 2031 & $0.97 \%$ & $1.30 \%$ & $1.72 \%$ & $1.28 \%$ & $0.02 \%$ & $0.02 \%$ \\
\hline 2032 & $1.01 \%$ & $1.34 \%$ & $1.72 \%$ & $1.28 \%$ & $0.03 \%$ & $0.02 \%$ \\
\hline 2033 & $1.05 \%$ & $1.39 \%$ & $1.72 \%$ & $1.28 \%$ & $0.03 \%$ & $0.02 \%$ \\
\hline 2034 & $1.10 \%$ & $1.43 \%$ & $1.72 \%$ & $1.28 \%$ & $0.03 \%$ & $0.02 \%$ \\
\hline 2035 & $1.14 \%$ & $1.48 \%$ & $1.72 \%$ & $1.28 \%$ & $0.03 \%$ & $0.02 \%$ \\
\hline 2036 & $1.19 \%$ & $1.53 \%$ & $1.72 \%$ & $1.28 \%$ & $0.03 \%$ & $0.02 \%$ \\
\hline 2037 & $1.23 \%$ & $1.58 \%$ & $1.73 \%$ & $1.28 \%$ & $0.03 \%$ & $0.02 \%$ \\
\hline 2038 & $1.28 \%$ & $1.63 \%$ & $1.73 \%$ & $1.29 \%$ & $0.03 \%$ & $0.02 \%$ \\
\hline 2039 & $1.34 \%$ & $1.68 \%$ & $1.73 \%$ & $1.29 \%$ & $0.03 \%$ & $0.02 \%$ \\
\hline 2040 & $1.39 \%$ & $1.73 \%$ & $1.74 \%$ & $1.29 \%$ & $0.03 \%$ & $0.02 \%$ \\
\hline 2041 & $1.45 \%$ & $1.79 \%$ & $1.72 \%$ & $1.28 \%$ & $0.03 \%$ & $0.02 \%$ \\
\hline 2042 & $1.50 \%$ & $1.85 \%$ & $1.70 \%$ & $1.26 \%$ & $0.04 \%$ & $0.03 \%$ \\
\hline 2043 & $1.57 \%$ & $1.91 \%$ & $1.68 \%$ & $1.25 \%$ & $0.04 \%$ & $0.03 \%$ \\
\hline 2044 & $1.63 \%$ & $1.97 \%$ & $1.66 \%$ & $1.23 \%$ & $0.04 \%$ & $0.03 \%$ \\
\hline 2045 & $1.70 \%$ & $2.03 \%$ & $1.64 \%$ & $1.22 \%$ & $0.04 \%$ & $0.03 \%$ \\
\hline 2046 & $1.76 \%$ & $2.10 \%$ & $1.63 \%$ & $1.21 \%$ & $0.04 \%$ & $0.03 \%$ \\
\hline 2047 & $1.84 \%$ & $2.16 \%$ & $1.61 \%$ & $1.19 \%$ & $0.04 \%$ & $0.03 \%$ \\
\hline 2048 & $1.91 \%$ & $2.23 \%$ & $1.59 \%$ & $1.18 \%$ & $0.04 \%$ & $0.03 \%$ \\
\hline 2049 & $1.99 \%$ & $2.31 \%$ & $1.58 \%$ & $1.17 \%$ & $0.04 \%$ & $0.03 \%$ \\
\hline 2050 & $2.07 \%$ & $2.38 \%$ & $1.56 \%$ & $1.16 \%$ & $0.05 \%$ & $0.03 \%$ \\
\hline
\end{tabular}
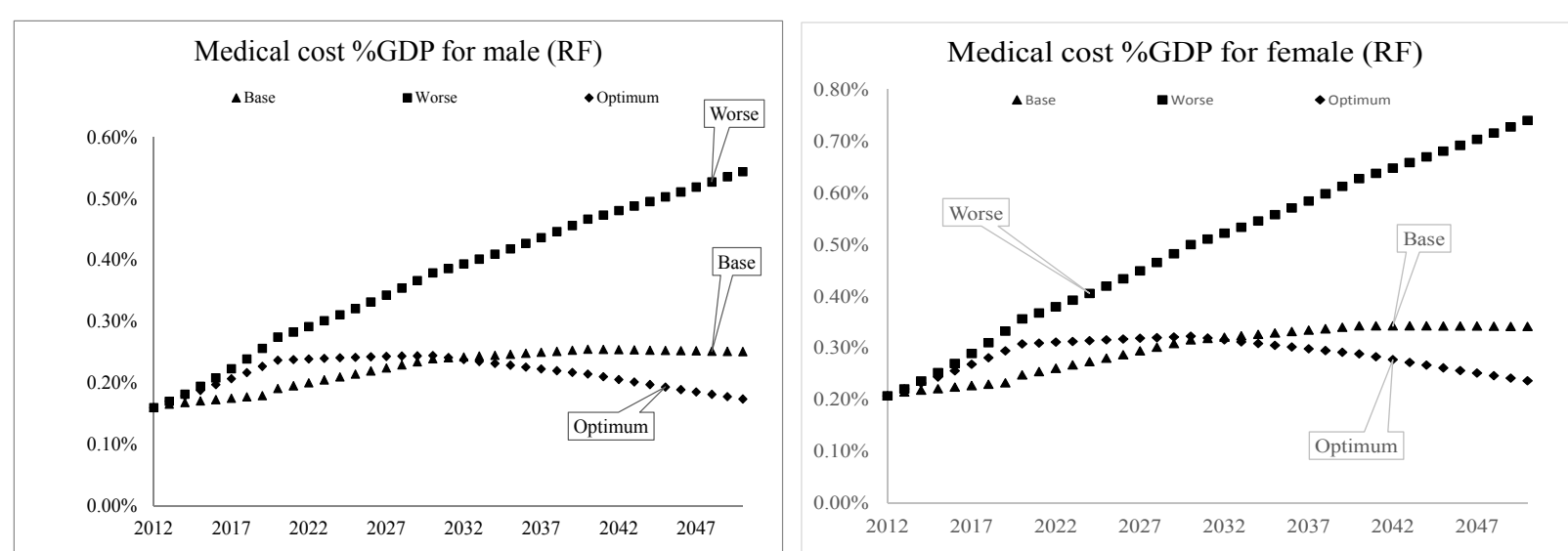

Fig. 3 Medical cost as a percentage of GDP for male and female since 2012 up to 2050 for three scenarios: base, optimum and worse. 

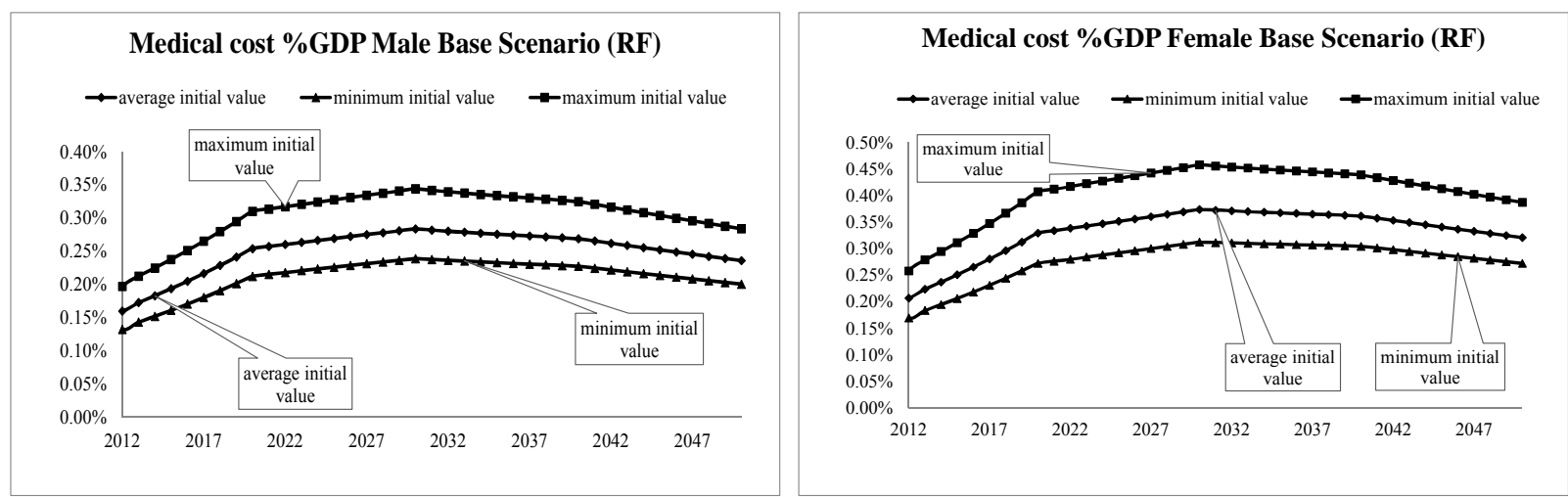

Fig. 4 Medical cost as a percentage of GDP for male and female for base scenario.
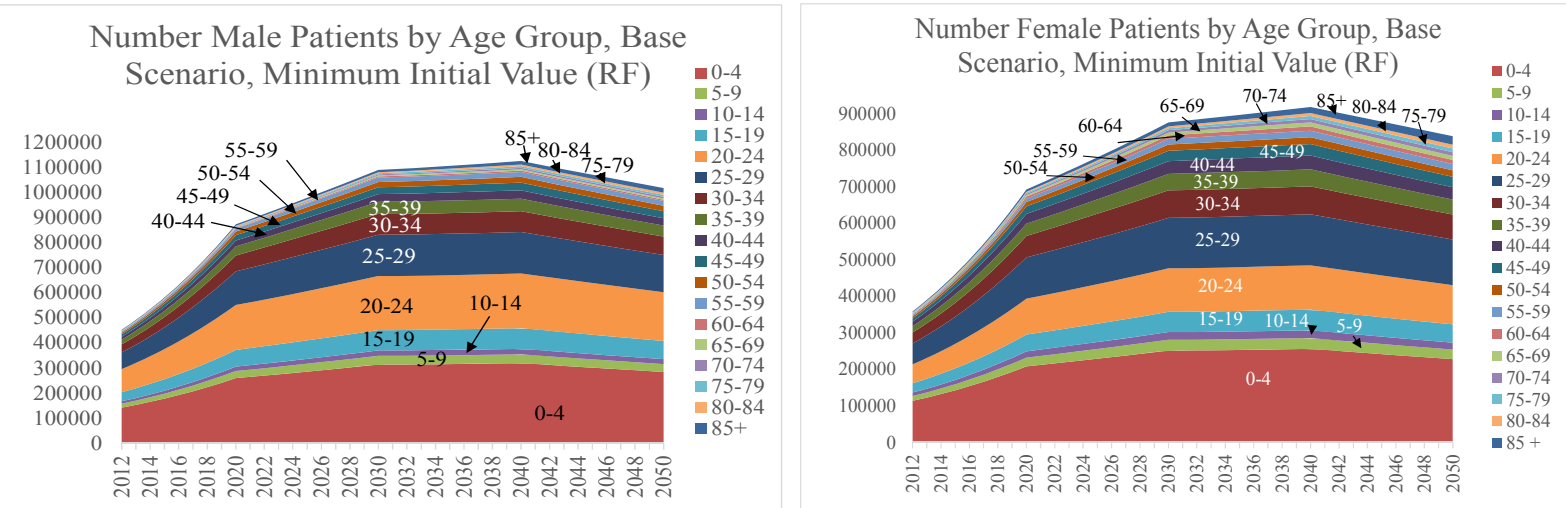

Fig. 5 Medical cost as a percentage of GDP for male and female for base scenario.
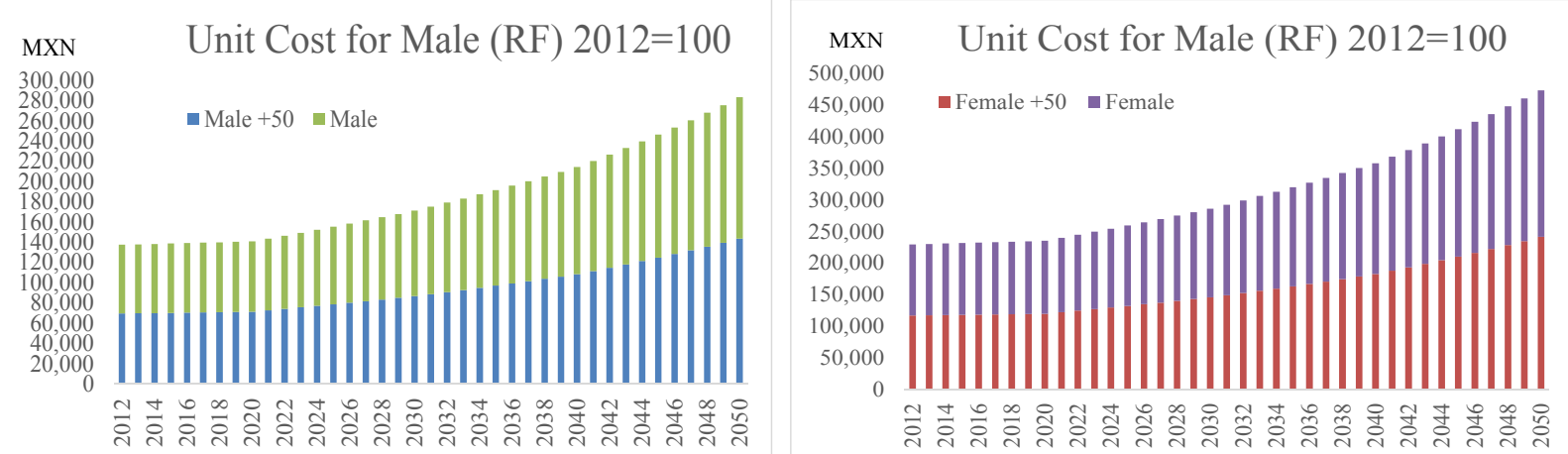

Fig. 6 Comparative unit cost for male and female all age group vs. 50 and more years old.
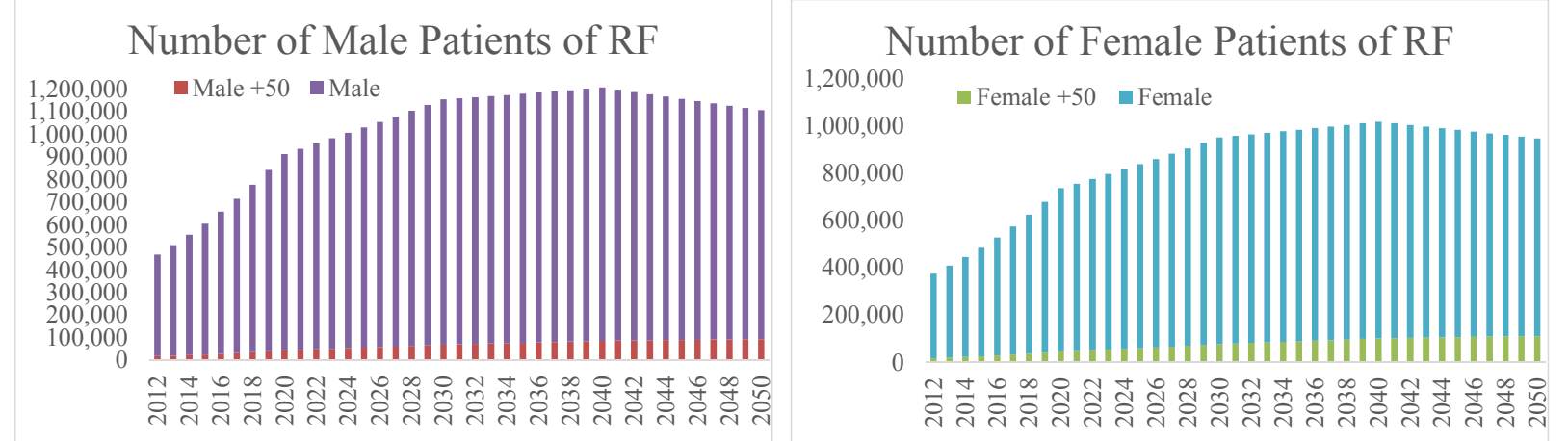

Fig. 7 Comparative number of patients of RF for male and female all age group vs. $\mathbf{5 0}$ and more years old. 


\section{Conclusions}

The renal failures are more expensive than diabetes mellitus [14] and hypertensive disease [15]. After of 50 years old RF increasing costs conceivably owing to others illness linking like neuronal diseases and renal failure. RF appears at early age 0-4 and 20-29 for both sex and increase from 70 years old. The RF is more expensive for female then male (unit cost). The male patient number is bigger than female. AMIS reported that there are more women $(51.18 \%)$ than men $(48.82 \%)$ insured by this disease. The different results are because of these patients belong to wage levels above 8 minimum wages and they acquired a major medical insurance.

It is necessary to construct consistent data bases for new cases and in treatment condition patient for age by sex by year to better models.

\section{References}

[1] (CELADE)—Division de Poblacion de la CEPAL. 2008. "Guideliness for the Modules Making on aging in the Dwelling Surveys. Latinoamerican and Caribean Center of Demography [Directrices para la elaboración de módulos sobre envejecimiento en las encuestas de hogares Centro Latinoamericano y Caribeno de Demografía]." Publicacion de las Naciones Unidas, ISSN version impresa 1680-886x ISSN version electronica 1680-8878 ISBN: 978-92-1-323244-6 LC/L.2969-P No de venta: S.08.II.G.81, Santiago de Chile.

[2] Academia Nacional de Medicina de Mexico, Academia Mexicana de Cirugia, Instituto de Geriatria, Universidad Nacional Autónoma de México. 2012. “Aging and Health: A Proposal for and Action Plan [Envejecimiento y salud: una propuesta para un plan de accion]." UNAM, México.

[3] Mullahy, J. 1986. "Specification and Testing of Some Modified Count Data Models." Journal of Econometrics 33 (December): 341-65.

[4] Database CONAPO. See link: http://www.conapo.gob.mx/es/CONAPO/ProyeccionesDa tos. The population projections of CONAPO are published along with demographic basic indicators and death data in its official web site.

[5] Instituto Mexicano del Seguro Social. "Finantial and Actuarial Report on December 31, 2009. [Informe Financiero y Actuarial al 31 de Diciembre de 2009.]".

[6] Instituto Mexicano del Seguro Social. "Finantial and
Actuarial Report on December 31, 2010. [Informe Financiero y Actuarial al 31 de Diciembre de 2010.]".

[7] Secretaría de Salud. 2006. "The mortality in Mexico 2000-2004, avoidable deaths: magnitude, distribution and tendencies [La mortalidad en México, 2000-2004. Muertes Evitables: magnitud, distribución y tendencias].” Subsecretaría de Innovación y Calidad Dirección General de Información en Salud, México.

[8] Secretaría de Salud, Sistema Nacional de Información en Salud, Dirección de Registros Administrativos, Departamento Explotación de Información Estadística. "Statistical Yearbooks, Mexico, 2013. [Anuarios estadísticos. México, 2013].” DE (ver http://www.sinais.salud.gob.mx/basesdedatos/),11/04/201 3.

http://www.sinais.salud.gob.mx/publicaciones/anuario.ht $\mathrm{ml}$. The National health information system (Sistema Nacional de Información en Salud, SINAI) presents in its official web site statistical yearbooks, newsletters statistical information, mortality and morbidity data, health accounts, health situation in Mexico (basic indicators), executive summaries, guides and manuals and other publications.

[9] Secretaria de Salud, Direccion General de Epidemiologia. "Morbility yearbooks, Mexico, 2013. [Anuarios de Morbilidad México 2013.]." DE (ver http://www.dgsi.salud.gob.mx), 11/04/2013. The General Management of Statistical Information (Dirección General de Información en Salud, DGIS) shows in its official web site demographics data and population projections and dynamic cubes to extract the necessary data.

[10] Secretaria de Salud. 2011. "Historical Information of Vital Statistics Births and Deaths 1893-2010 [Información histórica de estadísticas vitales nacimientos y defunciones 1893-2010]." Dirección General de Epidemiología, Subsecretaria de Prevención y Promoción de la Salud, ISBN 978-607-460-235-7, México.

[11] Villarreal-Ríos Enrique, Campos Esparza Maribel, Galicia Rodríguez Liliana, Martínez González Lidia, Vargas Daza Emma Rosa, Torres Labra Guadalupe, Patiño Vega Adolfo, Rivera Martínez María Teresa, Aparicio Rojas Raúl, and Juarez Duran Martin. 2011. "Annual Cost per Capital in the First Attention Level by Gender [Costo anual per cápita en primer nivel de atención por género].” Unidad de Investigación Epidemiológica y en Servicios de Salud Querétaro, Instituto Mexicano del Seguro Social, Ciencia y Saúde Coletiva 16 (3): 1961-8.

[12] Estudio Nacional de Salud y Envejecimiento en México (ENASEM) 2001 Documento Metodológico, Sistema de Cuentas Nacionales de México. 2012. "Satellite Account 
of the Health Sector of Mexico 2008-2010 [Cuenta satélite del sector salud de México 2008-2010].” INEGI, ISBN 978-607-494-316-0, México.

[13] Prajneshu. 1980. "Diffusion Approximations for Models of Population Growth with Logarithmic Interactions." Stochastic Processes and Their Application 10: 87-99, North-Holland Publishing Company.

[14] Ledesma, C. D. E., Hernandez, H. L., and Mucino, P. M. T. L. 2015. "Prospective of Medical Cost for Diabetes Mellitus for Sex and Age Group in Range 2012-2050:
Case of Mexico." In Proceedings of the International MultiConference of Engineers and Computer Scientists, 67-72, ISBN: 978-988-19253-9-8, ISSN: 2078-0958 (Print); ISSN: 2078-0966 (Online).

[15] Ledesma, C. D. E., Hernandez, H. L., and Mucino, P. M. T. L. 2015. "Longitudinal Analysis and Prospective of Medical Cost for Hypertensive Diseases: Case of Mexico." IOSR Journal of Engineering (IOSRJEN) ISSN (e): 2250-3021, ISSN (p): 2278-8719 Vol. 05, Issue 08 (August. 2015), Vol.4 pp. 11-21, www.iosrjen.org. 